\title{
Capability of Artificial Neural Networks for predicting long-term seasonal rainfalls in east Australia
}

\author{
$\underline{\text { F. Mekanik }}^{\mathrm{a}}$, M. A. Imteaz ${ }^{\mathrm{a}}$ \\ ${ }^{a}$ Faculty of Engineering and Industrial Sciences, Swinburne University of Technology, \\ Melbourne, VIC, Australia, \\ Email: fmekanik@groupwise.swin.edu.au
}

\begin{abstract}
Rainfall in southeast Australia is known to be affected by large scale climate modes variability. This study focused on investigating the use of lagged El Nino Southern Oscillation (ENSO) as potential predictors of spring rainfall in Victoria and Queensland in east Australia. Six rainfall stations including Bruthen, Buchan and Orbost in Victoria and Barcaldine, Kalamia and Augathella in Queensland were chosen as case study. Artificial Neural Network (ANN) approach was used as a nonlinear technique to capture this complex relationship. The Pearson correlation coefficients of past values of ENSO with spring rainfalls were calculated; it was discovered that the three months of June, July and August of Nino3.4, have significant correlation with spring rainfall. These correlations are very weak for Victoria and relatively higher for Queensland. These lag months of ENSO were incorporated into ANN models; i.e. the set of Nino3.4 (Jun-JulyAug) Was used as inputs for developing ANN models for the stations in Victoria and Queensland. Multilayer Perceptron (MLP) architecture was chosen for this purpose. The models were trained based on LevenbergMarquardt algorithm. ANN models showed higher correlation for Queensland compared to Victoria indicating that ANN is more capable of finding the pattern and trend of the observations in Queensland.
\end{abstract}

After calibrating and validating the models, in order to evaluate the generalization ability of the developed ANN models, out-of-sample tests were carried out. It was discovered that ANN models are showing very poor generalization ability for east Victoria regarding finding the pattern of the series $(r=-0.97,0.23$ and 0.67 for Bruthen, Buchan and Orbost respectively) compared to Queensland with correlation coefficients of $0.74,0.100$ and 0.98 for Barcaldine, Kalamia and Augathella respectively. This study shows the ability of ANN in finding nonlinear relationships between complex large scale climate models and rainfalls in southeast Australia.

Keywords: $\quad$ Artificial Neural Networks (ANN), rainfall, forecast, El Nino Southern Oscillation (ENSO) 


\section{INTRODUCTION}

Forecasting rainfall several months or seasons in advance can be beneficial for the management of water resources. Many researchers have tried to find the relationships between large-scale climate modes and rainfall in different parts around the world (Lau et al, 2001, Yufu et al, 2002, Hartmann et al, 2007, and Shukla et al, 2011). Australian rainfall is highly variable both in space and time. It is found that Australian rainfall is affected by several major climate patterns. The major drivers bringing rainfall over Australia which have been investigated by many researchers are El Nino Southern Oscillation (ENSO), Indian Ocean Dipole (IOD) and Southern Annular Mode (SAM) (Kirono et al, 2010). Many researchers have conducted different studies in different parts of Australia trying to establish the relationship between these climate modes and Australian rainfall. Some of these studies cover the whole Australia (Risbey et al, 2009, Meneghini et al, 2007 and Kirono et al, 2010) while the others are more focused on a specific region like South West Western Australia (SWWA) (Ummenhofer et al, 2008; and England et al, 2006), South Australia (Evans et al; 2009 and Nicholls, 2010), South East Australia (SEA) and East Australia (Verdon et al, 2004, Murphy and Timbal, 2008).Victoria is one of the regions that so far did not show good correlation of its rainfall and the climate modes. According to Verdon-Kidd \& Kiem (2009) in comparison to eastern Australia and particularly Queensland, past studies considering southeast Australian rainfall predictability could achieve a maximum of $30 \%$ correlation. In the work of Murphy and Timbal (2008) the maximum correlation, 0.37 , was obtained for spring rainfall and spring Nino4 index of ENSO. According to Verdon et al., (2004), compared to other parts of Australia ENSO signals are relatively weak in Victoria. This study will further investigate this matter by comparing the relationship between rainfall and ENSO in Queensland and Victoria in east Australia. The majority of studies on ENSO-rainfall relationships did not consider the effect of lagged climate modes on future rainfall predictions. According to Schepen et al., (2012) a strong relationship between simultaneous climate modes and rainfall does not essentially mean that there is a lagged relationship as well. Of the few studies focusing on the lagged climate - rainfall relationship one can mention Abbot and Marohasy (2012), Drosdowsky and Chambers (2001), Kirono et al., (2010), Mekanik and Imteaz (2012), Schepen et al., (2012) and Mekanik et al., (2013). Thus, the objective of this study is to investigate the relationship of lagged ENSO and spring rainfall in Victoria and Queensland, as two case studies. To achieve this objective Artificial Neural Network is used. Six rainfall stations are chosen in east Australia, three in eastern Victoria and three in eastern Queensland. Model outputs were aimed to be deterministic forecast as opposed to probabilistic forecast.

\section{Data}

Historical monthly rainfall data was obtained from the Australian Bureau of Meteorology for Bruthen, Buchan, Orbost in east Victoria and Barcaldine, Kalamia and Augathella in eastern Queensland, Australia as case studies. Figure 1 shows the location details of the stations considered in this study. Spring (September November) rainfall was obtained from monthly rainfall data from January 1900 to December 2009 (www.bom.gov.au/climate/data/). Also, monthly values of, Nino3.4 were used as ENSO indicator. ENSO indices were obtained from Climate Explorer website (http://climexp.knmi.nl/).

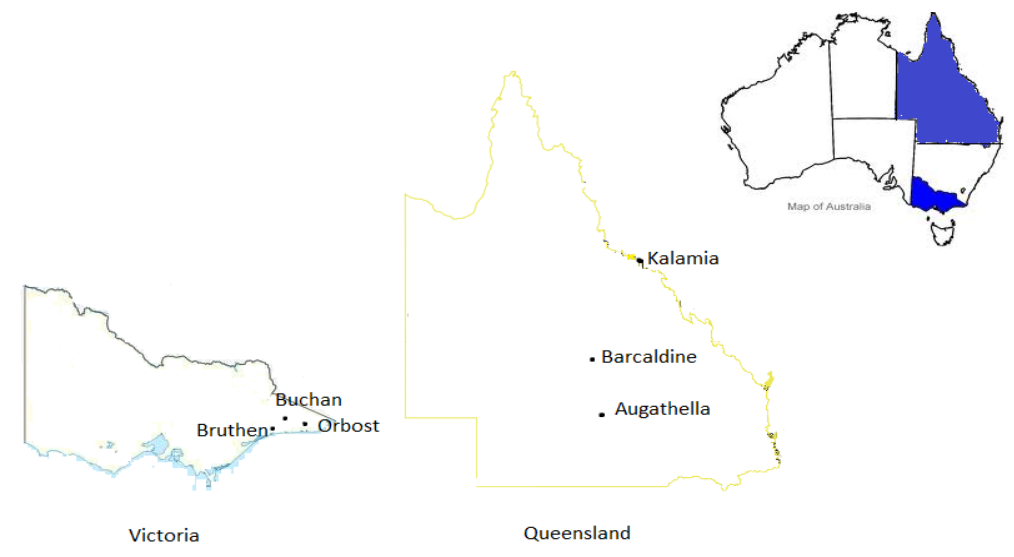

Figure 1. Map of the study area

\section{METHODOLOGY}

ANN has been used in many hydrological and meteorological applications; It has also been used for many 
cases of rainfall forecasting (Hsu et al., 1995; Luk et al., 2001; Mekanik et al., 2011; Toth et al., 2000, Yilmaz et al.,2011).

The parameters for ANN modelling are basically network topology, neurons characteristics, training and learning rules. Multi-Layered Perceptrons (MLP) are feed-forward nets with one or more hidden layers between the input and output neurons. The number of input and output neurons is based on the number of input and output data. Basically, the input layer only serves as receiving the input data for further processing in the network. The hidden layers are a very important part in a MLP since they provide the nonlinearity between the input and output sets. More complex problems can be solved by increasing the number of hidden layers or neurons. The output neuron is the desired output of the model. The process of developing an ANN model is to find a) suitable input data set, b) determine the number of hidden layers and neurons, and c) training and testing the network. Mathematically, the network can be expressed as follow:

$Y_{t}=f_{2}\left[\sum_{j=1}^{J} w_{j} f_{1}\left(\sum_{i=1}^{I} w_{i} x_{i}\right)\right]$

where $Y_{t}$ is the output of the network, $x_{i}$ is the input to the network, $w_{i}$ and $w_{j}$ are the weights between neurons of the input and hidden layer and between hidden layer and output respectively; $f_{1}$ and $f_{2}$ are the activation functions for the hidden layer and output layer respectively. According to Maier and Dandy (2000) if extrapolating beyond the range of the training data is needed it is recommended to use sigmoidal-type transfer functions in the hidden layers and linear transfer functions in the output layer. In this study $f_{1}$ is considered tansigmoid function which is a nonlinear function and $f_{2}$ is considered the linear purelin function defined as follow:

$f_{1}=\frac{2}{(1+\exp (-2 x))}-1$

$f_{2}(x)=x$

The ANN models were trained based on Levenberg-Marquardt algorithm; number of hidden neurons was chosen based on constructive algorithm. In ANN modeling there is always the chance of having an over fitted model. To avoid this problem in this study early stop technique is applied while training and validating the models. Through using this method, the network stops the training when the error over the validation set starts to increase while the error over training set is still decreasing; In this way the network avoids over fitting (Luk et al., 2000; Sarle, 1995). The data were divided in to three sets, from 1900-1990 for calibration and from 1991-2006 for validation of the models. Three years 2007-2009 were selected as the out-of-sample set to evaluate the generalization ability of the developed models. The data were normalized between the range of 1 and 0 using Eq. (4).

$\bar{x}_{i}=\frac{x_{i}-x_{\min }}{x_{\max }-x_{\min }}$

(4)

\section{RESULT AND DISCUSSION}

According to Lim et al., (2010) ENSO has a strong influence in the austral spring on eastern and southern Australia. Cheiw et al., (1998) also suggest that ENSO indicators can be used to some extent to forecast spring rainfall in eastern Australia; They found that the highest correlation between rainfall and climate indicators are obtained using SOI and SST values averaged over two or three months. On the other hand, Verdon et al., (2004) indicate that the influence of ENSO in Victoria (southeast Australia) appears to be weak.

In this study correlation between spring rainfall at year $n$ and $\operatorname{Dec}_{n-1}-A^{-} g_{n}$ monthly values of ENSO indicator (Nino3.4) were calculated (" $n$ " being the year for which spring rainfall is being predicted); It was discovered that the three months of June, July and August of Nino3.4 have the highest significant correlation with spring rainfall for both Victoria and Queensland (Table1); This result is in accordance to the findings of Cheiw et al., (1998) and Verdon et al., (2004), substantiating that not only the highest correlations between rainfall and climate indicators are obtained up to three month lags i.e. there is no further significant relationship after lag 3 for Victoria; It can be seen from Table 1 that these correlations are very weak for Victoria and are relatively higher for Queensland. 
These lag months of Nino3.4 were incorporated into ANN models; i.e. the set of Nino3.4 (Jun-July-Aug) was used as inputs for developing ANN models for the stations in Victoria and Queensland. Table 2 summarises the prediction skills of these models regarding MSE and Pearson correlation (r).

Table1. Pearson correlation (r) of lagged climate indices and spring rainfall

\begin{tabular}{|c|c|c|c|c|c|}
\hline \multirow[t]{2}{*}{ Region } & \multirow[t]{2}{*}{ Station } & \multicolumn{4}{|c|}{ Lagged climate indices } \\
\hline & & Nino34 $_{(\text {Jun })}$ & $\mathrm{Nino34}_{\text {(Jul) }}$ & Nino34 & \\
\hline \multirow[t]{3}{*}{ Victoria } & Bruthen & $-0.20^{\mathrm{b}}$ & $-0.25^{\mathrm{a}}$ & -0.28 & \\
\hline & Buchan & $-0.22^{b}$ & $-0.26^{\mathrm{a}}$ & -0.24 & \\
\hline & Orbost & --- & $-0.24^{b}$ & -0.26 & \\
\hline \multirow[t]{3}{*}{ Queensland } & Barcaldine & $-0.35^{\mathrm{a}}$ & $-0.32^{\mathrm{a}}$ & -0.35 & \\
\hline & Kalamia & $-0.31^{\mathrm{a}}$ & $-0.30^{\mathrm{a}}$ & -0.35 & \\
\hline & Augathella & $-0.32^{\mathrm{a}}$ & $-0.29^{\mathrm{a}}$ & -0.30 & \\
\hline \multicolumn{6}{|c|}{$\begin{array}{l}\text { a: correlation is significant at the } 0.01 \% \text { level } \\
\text { b: correlation is significant at the } 0.05 \% \text { level }\end{array}$} \\
\hline \multicolumn{6}{|c|}{ Table 2. Model performance for Queensland and Victoria } \\
\hline \multicolumn{3}{|c|}{ Queensland } & \multicolumn{3}{|c|}{ Victoria } \\
\hline Barcaldine & Kalamia & Augathella & Bruthen & Buchan & Orbost \\
\hline 0.04 & 0.01 & 0.02 & 0.04 & 0.03 & 0.02 \\
\hline 0.79 & 0.57 & 0.67 & 0.53 & 0.57 & 0.25 \\
\hline
\end{tabular}

It can be seen from Table 2 that the correlation coefficients of ANN models for Queensland is significantly higher compared to Victoria. Model errors are not significantly different for the two states except for Kalamia with an MSE of 0.01. The higher correlation coefficient of ANN models for Queensland indicate that ANN is more capable of finding the pattern and trend of the observations using the lagged Nino3.4 in Queensland compared to Victoria.

After calibrating and validating the models, in order to evaluate the generalization ability of the developed ANN models, out-of-sample tests were carried out on the years 2007-2009 (Table 3). It can be seen that ANN models are showing very poor generalization ability for east Victoria regarding finding the pattern of the series ( $r=-0.97,0.23$ and -0.67 for Bruthen, Buchan and Orbost respectively) compared to Queensland with correlation coefficients of $0.74,1.00$ and 0.98 for Barcaldine, Kalamia and Augathella respectively.

Table 3. Model performance for test sets

\begin{tabular}{ccccccc}
\hline & \multicolumn{3}{c}{ Queensland } & \multicolumn{3}{c}{ Victoria } \\
\cline { 2 - 7 } & Barcaldine & Kalamia & Augathella & Bruthen & Buchan & Orbost \\
\hline MSE & 0.04 & 0.00 & 0.05 & 0.02 & 0.03 & 0.05 \\
R & 0.74 & 1.00 & 0.98 & -0.97 & 0.23 & -0.67 \\
\hline
\end{tabular}

Figure 2 and 3 shows comparisons between ANN models for Victoria and Queensland. It can be seen from these figures that the models generally underestimate the observations. To further asses this matter mean and standard deviation of the models were evaluated (Table 4). It is obvious from Table 4 that the models have a mean close to the mean of the series however the standard deviation is lower indicating an underestimation of the observations. This means that lagged ENSO alone is not capable of predicting spring rainfall, other 
Mekanik and Imteaz, Capability of Artificial Neural Networks for predicting long-term seasonal rainfalls

climate modes like Indian Ocean dipole (IOD) and Southern Annual Mode (SAM) must be considered as well for this purpose.

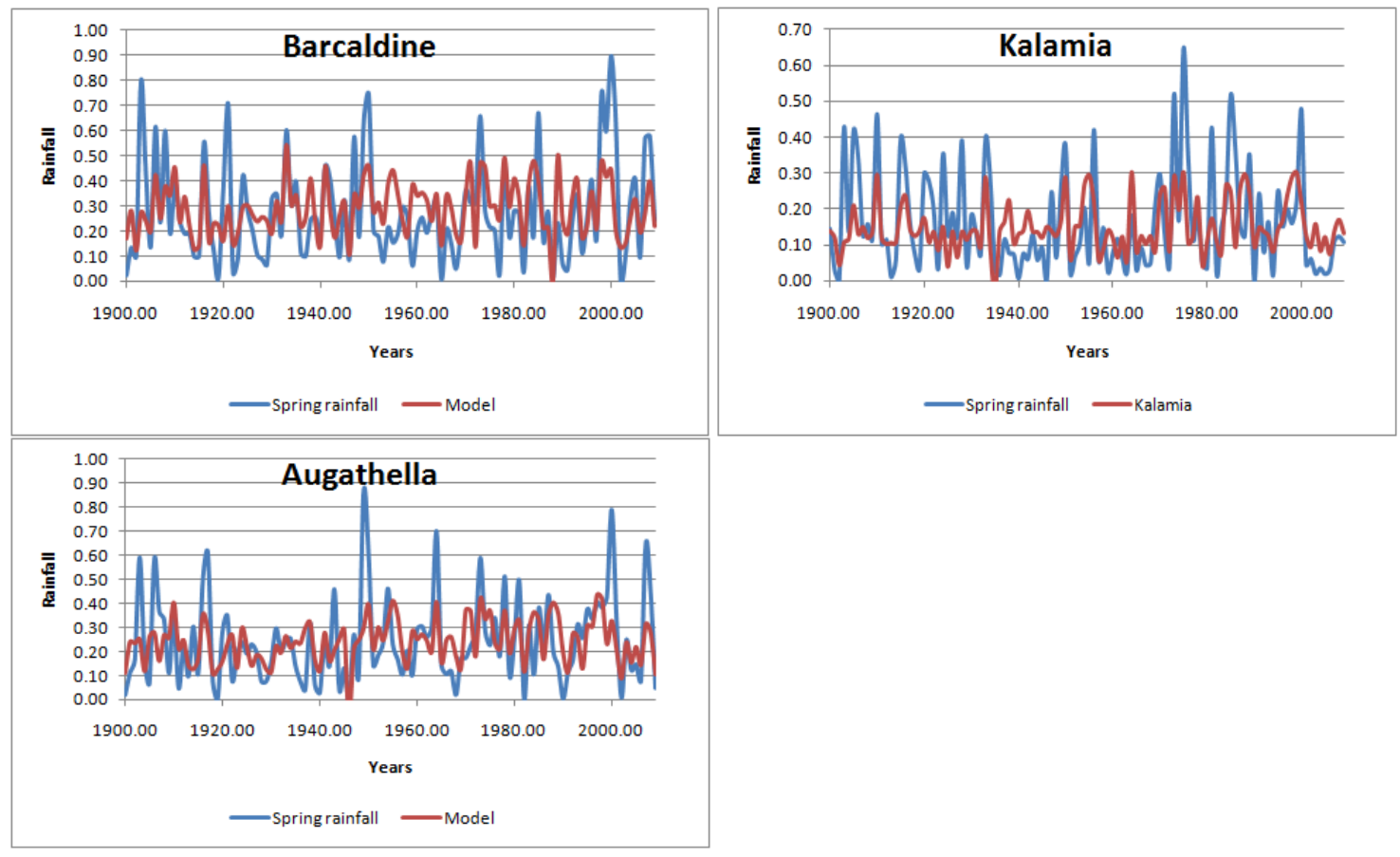

Figure 2. ANN models for Victoria

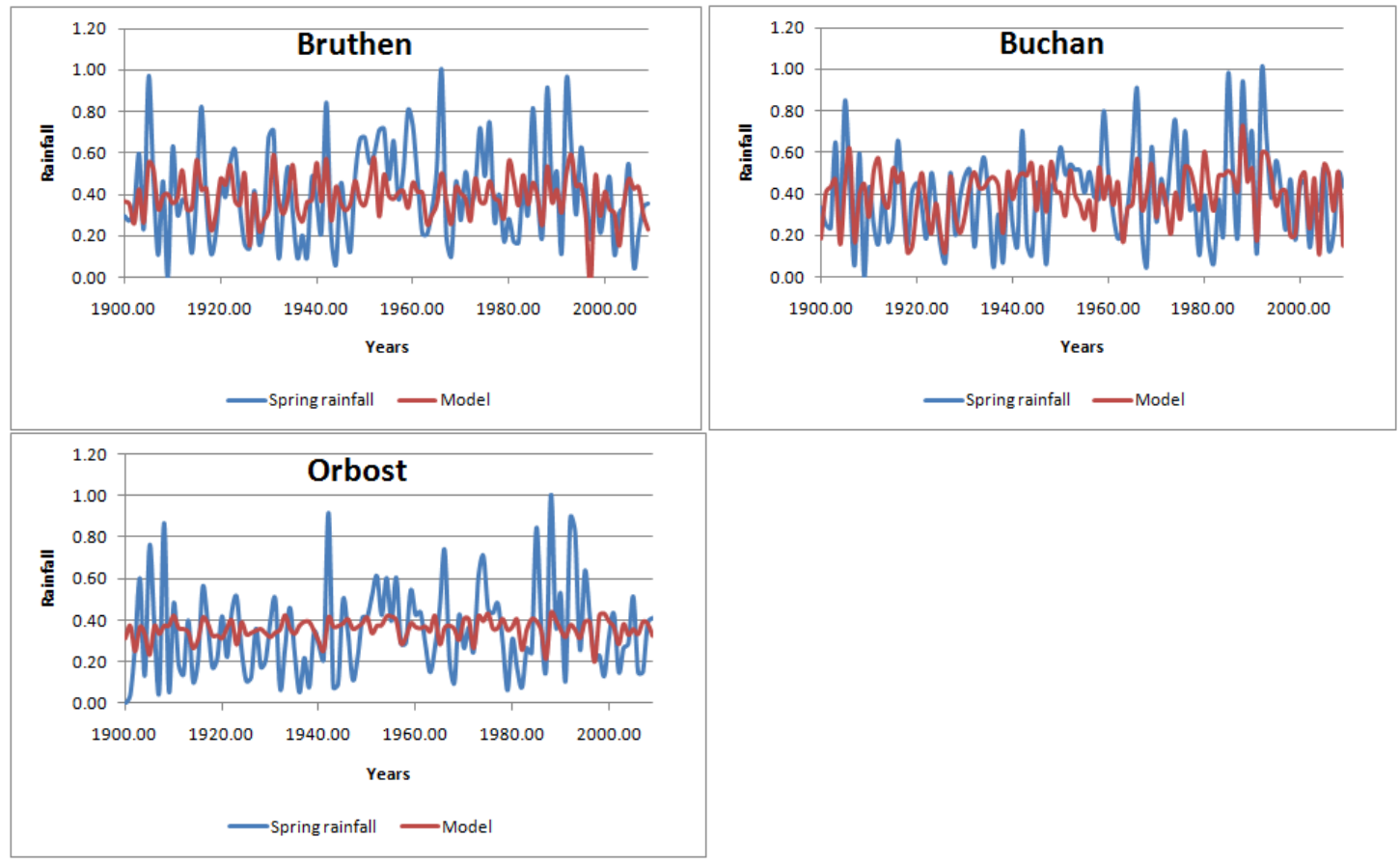

Figure 3. ANN models for Queensland 
Mekanik and Imteaz, Capability of Artificial Neural Networks for predicting long-term seasonal rainfalls

Table 4. Mean and standard deviation of the models and observations

\begin{tabular}{cccccc}
\hline \multirow{2}{*}{ Region } & Station & \multicolumn{2}{c}{ mean } & \multicolumn{2}{c}{ Standard.Dev } \\
\cline { 3 - 6 } Queensland & & Observation & Model & Observation & Model \\
& Barcaldine & 0.28 & 0.29 & 0.20 & 0.11 \\
& Kalamia & 0.16 & 0.15 & 0.14 & 0.07 \\
\multirow{2}{*}{ Victoria } & Augathella & 0.24 & 0.24 & 0.18 & 0.09 \\
& Bruthen & 0.40 & 0.38 & 0.23 & 0.10 \\
& Buchan & 0.39 & 0.40 & 0.22 & 0.13 \\
& Orbost & 0.34 & 0.36 & 0.21 & 0.05 \\
\hline
\end{tabular}

\section{CONCLUSION}

This study focused on investigating the use of lagged El Nino Southern Oscillation (ENSO) as potential predictors of spring rainfall; Nino3.4 was used as ENSO indicator. Artificial Neural Network (ANN) approach was used as a nonlinear technique to capture this complex relationship. Six stations in the two states of Victoria and Queensland were chosen as case study.

The Pearson correlation coefficients of past values of ENSO with spring rainfalls for the 6 stations were calculated; It was discovered that the three months of June, July and August of Nino34, have the highest significant correlation with spring rainfall. These correlations are very weak for Victoria and relatively higher for Queensland. These lag months of Nino3.4 were incorporated into ANN models; i.e. the set of Nino3.4 (JunJuly-Aug) Was used as inputs for developing ANN models for the stations in Victoria and Queensland.

Multilayer Perceptron (MLP) architecture was chosen for this purpose due to its wide use in hydrologic modellings. The models were trained based on Levenberg-Marquardt algorithm. ANN models showed higher correlation for Queensland compared to Victoria indicating that ANN is more capable of finding the pattern and trend of the observations in Queensland.

After calibrating and validating the models they were tested on out-of-sample sets. It was found that generalization ability of ANN models for Victoria is very poor compared to Queensland. ANN was able to perform out of sample test with correlation coefficient of $0.74 \sim 0.98$ for Queensland. This study shows the ability of ANN in finding nonlinear relationships between complex large scale climate modes and rainfalls in south-east Australia.

\section{REFERENCES}

Abbot, J., \& Marohasy, J. (2012). Application of artificial neural networks to rainfall forecasting in Queensland, Australia. Advances in Atmospheric Sciences, 29(4), 717-730.

Chiew, F., Piechota, T. C., Dracup, J., \& McMahon, T. (1998). El Nino/Southern Oscillation and Australian rainfall, streamflow and drought: Links and potential for forecasting. Journal of Hydrology, 204(1), 138149.

Drosdowsky, W., \& Chmabers, L. E. (2001). Near-global sea surface temperature anomalies as predictors of Australian seasonal rainfall. Journal of Climate, 14(7), 1677-1687.

England, M. H., Ummenhofer, C. C., \& Santoso, A. (2006). Interannual rainfall extremes over southwest Western Australia linked to Indian Ocean climate variability. Journal of Climate, 19(10), 1948-1969.

Evans, A. D., Bennett, J. M., \& Ewenz, C. M. (2009). South Australian rainfall variability and climate extremes. Climate Dynamics, 33(4), 477-493.

Hartmann, H., Becker, S., \& King, L. (2008). Predicting summer rainfall in the Yangtze River basin with neural networks. International Journal of Climatology, 28(7), 925-936.

Hsu, K., Gupta, H. V., \& Sorooshian, S. (1995). Artificial neural network modeling of the rainfall-runoff process. Water Resources Research, 31(10), 2517-2530.

Kiem, A. S., \& Verdon-Kidd, D. C. (2009). Climatic drivers of victorian streamflow: Is ENSO the dominant influence. Australian Journal of Water Resources, 13(1), 17-29.

Kirono, D. G. C., Chiew, F. H. S., \& Kent, D. M. (2010). Identification of best predictors for forecasting seasonal rainfall and runoff in Australia. Hydrological Processes, 24(10), 1237-1247.

Lau, K., \& Weng, H. (2001). Coherent modes of global SST and summer rainfall over China: An assessment of the regional impacts of the 1997-98 El Nino. Journal of Climate, 14(6), 1294-1308. 
Lim, E. P., Hendon, H. H., Anderson, D. L. T., Charles, A., \& Alves, O. (2011). Dynamical, statisticaldynamical, and multimodel ensemble forecasts of Australian spring season rainfall. Monthly Weather Review, 139(3), 958-975.

Luk, K., Ball, J., \& Sharma, A. (2000). A study of optimal model lag and spatial inputs to artificial neural network for rainfall forecasting. Journal of Hydrology, 227(1), 56-65.

Luk, K. C., Ball, J., \& Sharma, A. (2001). An application of artificial neural networks for rainfall forecasting. Mathematical and Computer modelling, 33(6), 683-693.

Maier, H. R., \& Dandy, G. C. (2000). Neural networks for the prediction and forecasting of water resources variables: a review of modelling issues and applications. Environmental Modelling and software, 15(1), 101-124.

Mekanik, F., Lee, T. S., \& Imteaz, M. A. (2011). Rainfall modeling using Artificial Neural Network for a mountainous region in west Iran. 19th International Congress on Modelling and Simulation MODSIM2011, Perth, November.

Mekanik, F. \& Imteaz, M. A. (2012). Forecasting Victorian spring rainfall using ENSO and IOD: A comparison of linear multiple regression and nonlinear ANN. International Conference on Uncertainty Reasoning and Knowledge Engineering, URKE 2012, Jakarta.

Mekanik, F., Imteaz, M. A., Gato-Trinidad, S., \& Elmahdi, A. (2013). Multiple regression and Artificial Neural Network for long-term rainfall forecasting using large scale climate modes. Journal of Hydrology, $503,11-21$.

Meneghini, B., Simmonds, I., \& Smith, I. N. (2007). Association between Australian rainfall and the Southern Annular Mode. International Journal of Climatology, 27(1), 109-121.

Murphy, B. F., \& Timbal, B. (2008). A review of recent climate variability and climate change in southeastern Australia. International Journal of Climatology, 28(7), 859-879.

Nicholls, N. (2010). Local and remote causes of the southern Australian autumn-winter rainfall decline, 1958-2007. Climate Dynamics, 34(6), 835-845.

Risbey, J. S., Pook, M. J., McIntosh, P. C., Wheeler, M. C., \& Hendon, H. H. (2009). On the remote drivers of rainfall variability in Australia. Monthly Weather Review, 137(10), 3233-3253.

Sarle, W. S. (1995). Stopped training and other remedies for overfitting. Paper presented at the Proceedings of the 27 th Symposium on the Interface.

Schepen, A., Wang, Q., \& Robertson, D. (2011). Evidence for using lagged climate indices to forecast Australian seasonal rainfall. Journal of Climate.

Shukla, R. P., Tripathi, K. C., Pandey, A. C., \& Das, I. M. L. (2011). Prediction of Indian summer monsoon rainfall using Niño indices: A neural network approach. Atmospheric Research, 102(1-2), 99-109.

Toth, E., Brath, A., \& Montanari, A. (2000). Comparison of short-term rainfall prediction models for realtime flood forecasting. Journal of Hydrology, 239(1), 132-147.

Ummenhofer, C. C., Sen Gupta, A., Pook, M. J., \& England, M. H. (2008). Anomalous rainfall over southwest Western Australia forced by Indian Ocean sea surface temperatures. Journal of Climate, 21(19), 5113-5134.

Verdon-Kidd, D., \& Kiem, A. (2009). On the relationship between large-scale climate modes and regional synoptic patterns that drive Victorian rainfall. Hydrology and Earth System Sciences, 13(4), 467-479.

Verdon, D. C., Wyatt, A. M., Kiem, A. S., \& Franks, S. W. (2004). Multidecadal variability of rainfall and streamflow: Eastern Australia. Water Resources Research, 40(10), W10201.

Yilmaz,AG.,Imteaz,MA. \& Jenkins, G. (2011). Catchment flow estimation using Artificial neural Networks in mountainous Euphrates basin. Journal of Hydrology, 410, 134-140

Yufu, G., Yan, Z., \& Jia, W. (2002). Numerical simulation of the relationships between the 1998 Yangtze River valley floods and SST anomalies. Advances in Atmospheric Sciences, 19(3), 391-404. 